\title{
ESTRATEGIAS DIGITALES DE DIFUSIÓN MUSEÍSTICA EN TIEMPOS DEL COVID-19. ESTUDIO COMPARATIVO ENTRE ECUAdOR, ESPAÑA Y PERÚ
}

\author{
Sebastián-Alberto Longhi-Heredia* \\ Universidad de Huelva \\ sebastianalberto.longhi@alu.uhu.es \\ LADDY LISET QUEZADA-TELLO** \\ Universidad de Huelva \\ laddy.quezada@alu.uhu.es \\ GiANCARLO CAPPELLO*** \\ Universidad de Lima \\ gcappell@ulima.edu.pe
}

Recibido: 23/6/2021 Aceptado: 20/9/2021

doi: https://doi.org/10.26439/contratexto2021.n036.5243

RESUMEN. Las estrategias de comunicación implementadas por los museos tras la crisis sanitaria del COVID-19 enfrentaron el cierre de las instituciones de cara al público. De allí la necesidad de contrastar cómo Ecuador, España y Perú actuaron para poner en evidencia la cultura y el patrimonio al alcance de la población. El estudio exploratorio fue abordado desde el análisis de contenido mixto. Se clasificaron y categorizaron las acciones implementadas por los museos en el contexto pandémico, tomando en cuenta el tipo de contenido y los recursos desplegados para llegar al público. Finalmente, se abocó a identificar las áreas estratégicas de acción de la UNESCO. La tendencia supranacional registrada cambia en función de la situación de cada país. En este sentido, se advirtió que las acciones desplegadas desde España entraron en adecuación con los informes internacionales. Desde Ecuador y Perú, las "actividades digitales" y las "actividades en redes sociales" resultaron ser más representativas que la media descrita por

\footnotetext{
* Magíster en Comunicación Social por la Universidad de Huelva (véase: https://orcid.org/0000-00018438-562X).

** Magíster en Comunicación Social por la Universidad de las Américas (véase: https://orcid.org/00000001-5717-1968).

*** Magíster en Literatura por la Pontificia Universidad Católica del Perú (véase: https://orcid.org/00000003-2908-6429)
} 
los informes. En el plano temático, el contenido difundido fue en su mayoría de orden comunicacional y educativo, quedando relegados los tópicos referidos a la investigación y la preservación.

PALABRAS CLAVE: museos / estrategias digitales / comunicación / redes sociales / COVID-19

\section{DIGITAL STRATEGIES FOR MUSEUM DISSEMINATION IN THE ERA OF COVID-19. A COMPARATIVE STUDY BETWEEN ECUADOR, SPAIN AND PERU}

ABSTRACT. The communication strategies implemented by the museums after the COVID-19 health crisis implied the closure of the institutions to the public. Hence the need to contrast how Ecuador, Spain and Peru acted by highlighting the culture and heritage available to the population. The exploratory study was approached through mixed content analysis. The actions implemented by museums in the context of the pandemic were classified and they categorized, taking into account the type of content and resources deployed to reach the public. Finally, focus was placed on identifying UNESCO's strategic areas of action. The supranational trend registered changes depending on the situation of each country. In this sense, it was noted that the actions deployed from Spain were in line with international reports. From Ecuador and Peru, the 'Digital Activities' and the 'Activities on Social Networks' turned out to be more representative than the average described by the reports. At the thematic level, the content disseminated was mostly of a communicational and educational nature, with topics related to research and preservation being relegated.

KEYWORDS: museums / digital strategies / communication / social networks / COVID-19 


\section{ESTRATÉGIAS DIGITAIS DE DIFUSÃO DE MUSEUS EM TEMPOS DE COVID-19. ESTUDO COMPARATIVO ENTRE EQUADOR, ESPANHA E PERU}

RESUMO. As estratégias de comunicação implementadas pelos museus quando da crise sanitária do COVID-19 implicou no fechamento das instituições ao público. Os países desenvolveram, em consequência, estratégias de comunicação digital a fim de aproximar-se do público. Daí a necessidade de comparar como o Equador, a Espanha e o Peru atuaram ao colocar em evidencia a cultura e o patrimônio e torná-los ao alcance da população. Este estudo foi abordado a partir de análises de conteúdo mista; ele classificou e categorizou as ações implementadas pelos museus no contexto pandêmico, levando em consideração o tipo de conteúdo e os recursos implantados para se chegar ao público. Finalmente, se empenhou, também, a identificar as áreas estratégicas de ação da UNESCO. A tendência supranacional registrada muda em função da situação de cada país. Nesse sentido, constatou-se que as ações desenvolvidas na Espanha estão alinhadas com os informes internacionais. No Equador e Peru, as "Atividades Digitais" e as "Atividades em Redes Sociais", revelaram ser mais representativas que a média descrita pelos relatórios. Já no nível temático, o conteúdo veiculado foi, predominantemente, comunicacional e educacional, sendo que não foram abordados os tópicos referentes à investigação e preservação.

PALAVRAS-CHAVE: museus / estratégias digitais / comunicação / redes sociais / COVID-19 


\section{INTRODUCCIÓN}

Según el Consejo Internacional de Museos (ICOM) y otros organismos supranacionales, entre el $90 \%$ y $95 \%$ de los 60000 museos en el mundo permanecieron cerrados como consecuencia de la pandemia por el COVID-19 (ICOM, 2020a; Organización de las Naciones Unidas para la Educación, la Ciencia y la Cultura [UNESCO], 2020a, 2020b). Ante esta coyuntura, se apeló a distintas vías para mantener el contacto con sus públicos, siendo las tecnologías digitales las que mejores logros han reportado. De hecho, ICOM (2020b) señala que cuatro de cada cinco museos han sido capaces de desenvolverse a través de servicios digitales, mientras que la Network of European Museum Organisations (NEMO, 2021) observa:

Las visitas han bajado considerablemente y no solo obligan a cuestionar los modelos de negocio y las medidas de éxito de los museos, sino a pedir nuevos enfoques e ideas para conectarse con sus audiencias y brindar acceso a sus colecciones de una manera significativa. (p. 2)

En efecto, muchos museos optaron por generar "recursos financieros alternativos, utilizando el entorno digital a través de recorridos virtuales y el uso de las redes sociales" (UNESCO, 2020c, p. 19), pero otros no contaron con la capacidad o la infraestructura para afrontar la crisis. Mientras que el $93 \%$ de los museos europeos aumentó o generó nuevos servicios en línea durante la pandemia, la situación en otros países estuvo regida por distintas circunstancias sociales y culturales (NEMO, 2021). En lo que concierne a lberoamérica:

Aunque casi la mitad de los encuestados respondieron que su museo ya estaba presente en las redes sociales, o compartía sus colecciones en línea antes de los cierres, las actividades de comunicación digital analizadas solo aumentaron en el $15 \%$ de los museos. (ICOM, 2020a, p. 2)

Este trabajo busca poner de relieve las estrategias de difusión implementadas por museos ecuatorianos, españoles y peruanos durante el auge de la crisis sanitaria por el COVID-19. En la medida que el trabajo da cuenta de los esfuerzos desplegados y publicados por las instituciones museísticas desde sus páginas web para mantener el contacto con la comunidad, el análisis recoge aquí como estrategias la variedad y combinación de canales y formatos de comunicación utilizados para permanecer en contacto con el público a partir de la generación de actividades y contenidos vinculados o derivados del quehacer museístico (tales como visitas 360, canales de streaming y podcast para conferencias o encuentros referidos a sus temas o colecciones, desarrollo de contenido lúdico y educativo para niños, entre otros que pueden apreciarse en la tabla 1). Así, el análisis categoriza las actividades digitales tomando en cuenta el tipo de contenido producido, los recursos desplegados y las herramientas de difusión para llegar 
al público. Finalmente, el texto se aboca a identificar las áreas estratégicas de gestión comunicacional organizándolas según los criterios de difusión empleados.

Es importante mencionar que desde el 2015 la UNESCO ya instaba a los museos a ser conscientes de que las tecnologías de la información y la comunicación (TIC) constituyen una oportunidad para asentarse como instituciones "al servicio de la sociedad y de su desarrollo, abiertas al público, que [...] comunican y exponen el patrimonio material e inmaterial de la humanidad y medio ambiente con fines de educación, estudio y recreo" (UNESCO, 2015, p. 27). En este sentido, las nuevas tecnologías en el ambiente de los museos contemporáneos son una de las puertas de avance e integración que ha encaminado hacia la generación de una sinergia entre las narrativas digitales y las necesidades de consumo cultural por parte del visitante. Según la investigación de Ruiz Torres y Bellido Gant (2017), la aplicación de los dispositivos portátiles dentro de los espacios expositivos, la opción de búsqueda de información, la personalización de contenidos y la facilidad de integrar una variedad de idiomas para que la información sea comprendida por los diversos usuarios que hacen uso de la actividad museística, en suma, la introducción de estas estrategias digitales viene a enriquecer las actividades de difusión cultural museísticas, siendo la realidad aumentada la que se encuentra a la cabeza de la difusión de contenidos culturales (Ruiz Torres, 2011) en aras de una mejor interpretación del bien cultural (Ruiz Torres y Bellido Gant, 2017; Satta, 2017).

En conclusión puede decirse, con base en el estudio de Díaz Salamanca et al. (2019), que es a partir del uso de estas tecnologías y las aplicaciones tridimensionales que se contribuye a la didáctica de la educación, la difusión de la cultura y el patrimonio generándose alteraciones sociales importantes.

\section{Museos y COVID-19. Un panorama general}

Desde la década de 1960, la UNESCO promueve la concepción de los museos como instituciones orientadas a reforzar la educación, la coexistencia y comprensión de la sociedad. En esa línea se definieron cuatro funciones esenciales reseñadas en la "Recomendación relativa a la protección y promoción de los museos, su diversidad y su función en la sociedad" (UNESCO, 2015):

- Preservación: que comprende actividades vinculadas con la adquisición y gestión de sus colecciones, que incluyen su conservación preventiva y correctiva, así como la seguridad de sus piezas en exhibición y en depósito.

- Investigación: orientada al estudio y reflexión histórica de las colecciones en el contexto contemporáneo.

- Comunicación: además de actividades culturales y actos públicos presenciales o a través de plataformas digitales, este acápite promueve la difusión activa de los conocimientos sobre las colecciones, los monumentos y los sitios. 
- Educación: función que cumplen a través de la concepción y transmisión de talleres, cursos y programas de corte educativo y pedagógico.

La crisis sanitaria provocada por la pandemia generó un clima de incertidumbre a nivel mundial. El 12,8 \% de los encuestados en un informe de ICOM (2020a) afirmó que sus museos podrían haber cerrado permanentemente, ya que se esperaban recortes en el $80 \%$ de los programas y casi un tercio había tenido que reducir personal drásticamente. Ante esta coyuntura, la UNESCO se enfocó en apoyar a sus Estados miembros con el soporte de entidades locales, nacionales e internacionales, como el Consejo Internacional de Museos (ICOM) o la American Alliance of Museums (2020a, 2020b, 2020c). Se trató de un amplio despliegue de recomendaciones para construir y desarrollar una eficiente comunicación con sus públicos durante los periodos de aislamiento, poniendo énfasis en la necesidad de construir un vínculo lúdico y educativo a través del uso creativo de distintas herramientas y soportes de fácil acceso (ICOM, 2020c).

Aunque no todos los países tuvieron la misma capacidad de reacción, se ha podido constatar que siguieron parámetros básicos como la "digitalización de las colecciones y la creación de museos virtuales" (UNESCO, 2020b, p. 15), muchos de los cuales ya estaban a disposición antes del confinamiento. Asimismo, las plataformas y redes sociales (Facebook, Twitter, Instagram) fueron las actividades de mayor dinámica destacando los recursos de formación y talleres de corte educativo. En paralelo, los museos ofrecieron actividades muy variadas destinadas a su público: "juegos, plantillas para colorear, concursos, actividades educativas y 'desafíos', muchos de los cuales contaron con el apoyo y difusión de la prensa" (UNESCO, 2020c).

Tomando en cuenta que la posibilidad de compartir investigación y transmitir el conocimiento de sus colecciones en diversos formatos está en relación directa con sus extensiones en internet (Riofrío Flores et al., 2019), los museos debieron asegurar:

(1) La digitalización de las colecciones, que a su vez se basaron en (2) un inventario suficientemente actualizado de las mismas; (3) infraestructura mínima (toma de fotografías, escáner, computadoras); (4) conexión a internet suficientemente estable; y (5) personal dedicado con las habilidades necesarias para realizar diversas operaciones. (UNESCO, 2020b, p. 16)

Como resultado de estos esfuerzos, el informe ICOM (2020a) confirmó un crecimiento del tráfico y de las actividades digitales, entre las que destacan especialmente las redes sociales, que aumentaron su interacción en un 41,9 \% (véase la figura 1).

Los museos vivieron realidades diferentes en el 2020. Mientras que la mayoría reabrió en Europa y Asia, los de Latinoamérica y el Caribe permanecieron cerrados o con actividades públicas suspendidas. Esto no impidió que se esforzaran por implementar y mejorar sus actividades digitales. Comparando los informes del ICOM de inicio y fines 
de año, se constató que "las categorías de difusión aumentaron en al menos el $15 \%$ de los museos del mundo, cifra que crece considerablemente cuando se observan canales como las redes sociales, los eventos de transmisión en vivo o los programas educativos en línea" (ICOM, 2010a, 2020b).

No Sí, igual que antes $\square$ Sí, aumentó después del cierre $\square$ Comenzó después del cierre

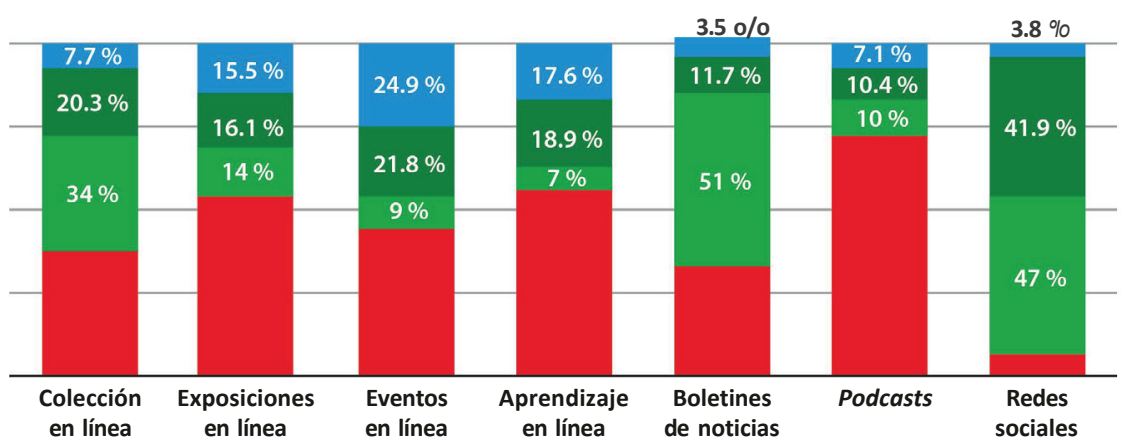

Figura 1. Cambios en las actividades digitales

Fuente: Reproducido del Informe ICOM (2020b) (https://icom.museum/wp-content/uploads/ 2020/05/Informe-museos-y-COVID-19.pdf)

Atendiendo todo lo descrito, la mayoría de los museos se apoyaron en un sistema digital preexistente fruto de inversiones anteriores. Mientras que un número mucho menor debió potenciar sus capacidades (infraestructura y personal) para presentar versiones digitales de exposiciones o actividades durante el confinamiento, las redes sociales siguieron utilizándose como antes de la crisis sanitaria, agregándose a la función de los medios de comunicación algunas cualidades vinculadas al entretenimiento o la distensión. Finalmente, los museos de Europa occidental (en comparación con Europa del Este, América Latina y el Caribe y los Estados Árabes) fueron los que evidenciaron mayor capacidad digital instalada para mantener el contacto con su público, así como para producir herramientas adaptadas al confinamiento (UNESCO, 2020b, p. 18).

\section{Estado de alarma, excepción y cierre de museos durante la crisis sanitaria}

\section{La situación de Ecuador}

En los últimos años la actividad museológica en Ecuador se apoyó en el Plan Nacional de Desarrollo "Toda una vida 2017-2021", del que parten las políticas relacionadas con los museos, patrimonio e interculturalidad. En su punto 2.2 se plantea: "Garantizar la interculturalidad y la plurinacionalidad en la gestión pública, para facilitar el goce efectivo de los derechos colectivos de los pueblos y nacionalidades" (Secretaría Nacional de 
Planificación y Desarrollo [Senplades], 2017, p. 63). La responsabilidad del patrimonio en Ecuador recae entonces en los gobiernos autónomos descentralizados (GAD) (Asamblea Nacional del Ecuador, 2010). El Código Orgánico de Organización Territorial (Asamblea Nacional del Ecuador, 2010), en el artículo 4, indica al respecto:

Artículo 4.- Fines de los gobiernos autónomos descentralizados

Dentro de sus respectivas circunscripciones territoriales son fines de los gobiernos autónomos descentralizados: [...] (e) La protección y promoción de la diversidad cultural y el respeto a sus espacios de generación e intercambio; la recuperación, preservación y desarrollo de la memoria social y el patrimonio cultural.

Teniendo en cuenta este contexto, existen cerca de 175 museos en el registro de la Red Ecuatoriana de Museos (Ministerio de Cultura y Patrimonio del Ecuador, 2018) que se clasifican como públicos, privados, eclesiásticos y comunitarios. La mayor cantidad se focaliza en el Distrito Metropolitano de Quito, Cuenca y Guayaquil.

Al momento del inicio de la pandemia, el presupuesto dirigido al Ministerio de Cultura y Patrimonio, al igual que a los GAD municipales, se vieron limitados por el recorte que el Ministerio de Finanzas impuso para priorizar la lucha contra la pandemia. En este escenario, mediante Decreto Ejecutivo 1017 del 16 de marzo del 2020, se dispuso la declaración de estado de excepción por calamidad pública en todo el territorio nacional, quedando la movilización restringida a todos los sectores no "prioritarios" (Secretaría General de Comunicación de la Presidencia, 2020).

Las limitaciones digitales de los museos ecuatorianos (previas a la pandemia) se tradujeron en un reto, ya que las instituciones debieron emplear estrategias de difusión que permitieran la creación de actividades durante el periodo de confinamiento. Por esta razón, el uso de las redes sociales se convirtió en una oportunidad para establecer contacto con los visitantes de los museos, artistas, estudiantes, existiendo un gran acercamiento a las instituciones educativas que buscaban contenido cultural.

El estado de excepción culminó en septiembre del 2020. Sin embargo, el proceso de reapertura de los museos siguió las pautas previstas por el manual denominado Protocolo General de Bioseguridad para la prevención de contagio del COVID-19 en museos de sitio de áreas arqueológicas y paleontológicas. Este se basó en las indicaciones emitidas por el Comité de Operaciones de Emergencias (COE Nacional), desde donde el Instituto Nacional de Patrimonio Cultural (INPC, 2020) limitó el aforo para los visitantes:

Los museos [...] deberán observar los horarios de atención establecidos por el COE Nacional. De igual manera en lo relacionado con el aforo se deberá reducir a 1/3 en cada uno de los espacios cerrados y en espacios públicos se actuará conforme lo establecido en la resolución del COE del 14 de marzo del 2020 donde se reduce a un máximo de 30 personas, cumpliendo obligatoriamente el distanciamiento entre personas (2 metros) y la capacidad máxima. (p. 6) 
Como parte de las estrategias para asegurar las visitas presenciales, algunas instituciones culturales aplicaron la venta de boletos virtuales para llevar el control de aforo. En este contexto, el Centro de Arte Contemporáneo, a través de su cuenta de Facebook, agradeció a los visitantes la reserva de entradas en línea y se unió a la solicitud de los otros museos para organizar estrategias gubernamentales que eviten mayor afectación al presupuesto y sostenibilidad de las actividades de las instituciones culturales del país.

\section{La situación de España}

Las instituciones museísticas en España están regidas por el Ministerio de Cultura y Deporte, la Dirección General de Bellas Artes y la Subdirección General de Museos Estatales, recayendo en los propios museos la conservación, investigación, comunicación y exhibición "para fines de estudio, educación y contemplación [de] conjuntos y colecciones de valor histórico artístico, científico y técnico o de cualquier otra naturaleza cultural" (Ley 16/1985, Ley del Patrimonio Histórico Español, 1985). Según datos oficiales del programa de cooperación para los museos de Iberoamérica (Ibermuseos, 2018), España posee 1481 instituciones museísticas, las cuales se clasifican de acuerdo con la tipología establecida por la UNESCO (Ministerio de Cultura y Deporte de España, 2020a, p. 275).

En lo que concierne a los museos españoles, se cumplieron las normas propuestas por los Gobiernos en materia de reapertura de los espacios públicos y privados tras la declaración del estado de alarma el 14 de marzo del 2020, el cual confinó a la población por un periodo de 15 días (Consejo de Ministros, 2020). En este sentido, se publicó el 9 de mayo del 2020 la Orden SND/399/2020 en el Boletín Oficial del Estado (BOE) para la flexibilización de algunas de las restricciones en el ámbito nacional que habían sido aplicadas en virtud del Plan para la Transición hacia una Nueva Normalidad (Ministerio de Cultura y Deporte de España, 2020b, p. 5). Conforme a este, en la fase 1 se permitió la apertura de las salas de los museos (colección permanente y exposiciones temporales, dejando fuera las actividades culturales y educativas). La fase 2 introdujo la apertura de exposiciones temporales y, finalmente, la fase 3 permitió el acceso del público a los museos, esta vez con visitas y actividades culturales y educativas.

Paralelamente a esta desescalada, se gestionaron accesos virtuales a las colecciones. En este sentido, el informe del Ministerio de Cultura y Deporte de España (2020b) planteaba:

Cuando el formato de la actividad lo permita, se habilitarán canales de participación no presencial (retransmisión en streaming, difusión posterior online [...] Se reforzará el diseño de recursos educativos, científicos y divulgativos de carácter digital, que permitan al museo cumplir su función como institución educativa y transmisora de conocimiento, por medios alternativos a los presenciales. (p. 14)

En líneas generales primó en España una política a corto plazo, en donde la reapertura gradual y paulatina no consideraba la presencia física en las instituciones culturales, 
ni la afluencia masiva de público, tampoco exposiciones de impacto y realizaciones de actividades socioeducativas grupales. En este sentido, desde la máxima institución cultural española se fomentaron las prácticas digitales:

Es momento para avanzar en el tratamiento digital de las colecciones y ofrecer los contenidos del museo de forma imaginativa a través de diferentes formas de comunicación virtual [...] repensar las dinámicas educativas y las actividades culturales de los museos, que deberán adaptarse creativamente a formatos más restringidos [...] es el momento de reforzar la investigación y preservación del patrimonio y prepararlo para su difusión cuando se recupere plenamente la normalidad [...] es la oportunidad de empezar a medir la relevancia de una institución a través de nuevos parámetros tales como la sostenibilidad y una gestión comprometida con la responsabilidad social. (Ministerio de Cultura y Deporte de España, 2020, p. 16)

En aras de este llamado y tal como lo constata la Presidencia de Gobierno de España (2021), se incrementaron las visitas culturales en línea, así como la interacción en redes sociales producto del confinamiento domiciliario. En contraste con el descenso de las visitas presenciales, se produjo un incremento notable de interacción con el público a través de las redes sociales, tal y como lo registran las cifras del Museo del Prado, el Museo Reina Sofía y el Museo Nacional Thyssen-Bornemisza (Presidencia de Gobierno de España, 2021). En línea con esta tendencia, tras la reapertura de los museos (luego de la fase de desescalada marcada por el Gobierno) se mantuvieron los contactos en línea: el NEMO señala que casi el $50 \%$ de los museos mantuvo las visitas en línea, conservando los mismos niveles desde que abrieron sus puertas, o aumentando considerablemente. Con ello:

Las ofertas digitales más populares para las audiencias en línea desde el inicio de la pandemia COVID-19 fueron las actividades realizadas en las redes sociales, que casi el $60 \%$ de los museos informaron que ya eran populares antes de la crisis sanitaria, seguido por el contenido de video (42\%) y los recorridos virtuales (28\%). (NEMO, 2021, p. 5)

En líneas generales, en España, el $96 \%$ de los museos reabrió tras el cierre, aunque el $30 \%$ lo hizo con menos salas o con un horario restringido (Observatorio de Museos de España, 2020) manteniendo un formato mixto (virtualidad y presencialidad controladas). Asimismo, el estudio de Asociación de Conservadores Restauradores de España (ACRE, 2020), titulado "Impacto económico de la COVID-19 en el sector de la ConservaciónRestauración", explicó cómo las pérdidas económicas afectaron las actividades debido a la inestabilidad del sector de la conservación-restauración.

\section{La situación del Perú}

En el Perú existen museos estatales (nacionales, regionales, municipales, comunitarios o de sitio) y museos privados (organizaciones particulares, fundaciones, sociedades, 
asociaciones e instituciones religiosas y educativas) (Ministerio de Cultura del Perú, 2012). A diferencia de los estatales, los privados cuentan con libertad de acción, aunque todos mantienen contacto con el Ministerio de Cultura y se alinean con la Ley de Patrimonio y los programas como el de Museos Abiertos. Históricamente, se ha otorgado un mayor valor a las expresiones artísticas y contemporáneas, debido a que responden a intereses de coleccionistas privados y del mercado del arte. Circunstancia que también ha movilizado sus intereses de extensión y comunicación con el público.

En Lima, el $72 \%$ de los museos ha digitalizado su colección a través del registro fotográfico y usan preferentemente las redes sociales como Facebook para conectar con su público (Alvarado, 2018). Sin embargo, solo el 41 \% cuenta con un sistema digital de manejo de colecciones (Riofrío et al., 2019), por lo que menos de la mitad de los museos tiene registro de su patrimonio cultural a disposición del público. A la luz de estas cifras, el sector se considera en esta investigación como no digitalizado. Por ejemplo, solo el $7 \%$ ofrece servicio de audioguías o aplicaciones móviles (Alvarado, 2018). Por otro lado, se constata que, desde el sector público, a partir de agosto del 2019, 23 de los 50 museos que administra el Estado pueden ser visitados de forma virtual a través de una página web (Ministerio de Cultura del Perú, 2020). Asimismo, los internautas tienen la posibilidad de complementar su visita a través de fotografías y modelos 3D de algunas piezas y guías de audio (Ibermuseos, 2020). En grandes líneas, los museos privados son los que evidencian un mayor trabajo digital.

Ante la crisis sanitaria ligada al COVID-19, el país tomó medidas que suspendieron y condicionaron el trabajo de distintas instituciones. En marzo del 2020, el Decreto Supremo 044-2020-PCM que declaró el Estado de Emergencia Nacional señalaba en su artículo 7:

7.3 Se suspende el acceso al público a los museos, archivos, bibliotecas, monumentos, así como a los locales y establecimientos en los que se desarrollen espectáculos públicos, actividades culturales, deportivas y de ocio. (Decreto Supremo 044-2020)

Tras una larga cuarentena hasta el mes de junio del 2020, las actividades de los rubros vinculados a la producción y las finanzas se retomaron con restricciones e instrucciones precisas; sin embargo, no se consideró en este paquete a las actividades museísticas y culturales. Recién en el mes de diciembre, a través del Decreto Supremo 201-2020-PCM, se establecieron restricciones focalizadas en función del nivel de alerta de cada región. Solo entonces pudieron abrir teatros, museos y sitios arqueológicos, ateniéndose a un aforo variable cada 15 días (Decreto Supremo 201-2020). En las zonas geográficas con nivel de alerta sanitaria extrema, por ejemplo, el aforo permitido para bibliotecas, museos, monumentos arqueológicos, centros culturales y otros fue del $30 \%$. En el nivel muy alto, la cifra aumenta a $40 \%$, y en aquellas zonas con alerta alta a 
$50 \%$. Estas condiciones persisten al cierre de este trabajo (Gobierno del Perú, 2021), lo que muestra una constante: desde el Estado no ha habido consideraciones, incentivos o paliativos referidos a la actividad museística y cultural desde el inicio de la pandemia.

Es preciso señalar que la actividad digital de los museos privados contrasta con la de los nacionales en este tiempo. Mientras que los segundos permanecieron cerrados y sus plataformas digitales apenas mostraron alguna diversificación de contenidos, los primeros fueron muy dinámicos desde el inicio de la crisis sanitaria organizando, sobre la capacidad digital ya instalada, nuevas dinámicas y contenidos para no perder contacto con su público. Además de ofrecer materiales diversos y conferencias que sintonizaban con las necesidades de la educación a distancia, se convirtieron en caja de resonancia de las necesidades de los grupos artesanales y comunidades con las que habitualmente han trabajado, así como promotores de iniciativas solidarias diversas.

\section{METODOLOGÍA}

Como lo confirma el trabajo de Schweibenz (2019), los museos virtuales existen incluso antes de la llegada de internet: "Los primeros años del museo virtual se caracterizaron por aplicaciones multimedia e hipermedia en CD-ROM y computadoras independientes" (p. 4). De modo que, en este estudio, se abordará la virtualidad desde un punto de vista cambiante, ya que "incluyen una variedad de términos que todavía existen [...] por ejemplo, museo digital, museo electrónico, museo en línea, museo hipermedia, museo web o cibermuseo" (p. 21).

A fin de revisar las estrategias orientadas al público que desplegaron los museos en tiempos de pandemia, se realizó un trabajo exploratorio alrededor de sus acciones, agrupándolas de acuerdo con las principales áreas UNESCO y funciones esenciales. A partir de esta información se efectuó un trabajo de análisis mixto a fin de poner de relieve sus alcances a través de la implementación y desarrollo de acciones asociadas a la virtualidad y al mundo digital.

Estas actividades se agruparon tras haber estudiado los textos internacionales de la UNESCO, el ICOM y el NEMO. En consecuencia, las categorías empleadas se organizaron en función de (1) las propuestas digitales ya existentes; (2) aquellas organizadas durante la pandemia del COVID-19; (3) las habilidades de animación en las redes sociales; y (4) la creación de nuevas actividades específicas (científicas y profesionales). En este sentido, la figura 2 muestra la distribución base obtenida en función del tipo de estrategias generadas desde los museos durante los primeros meses de la pandemia en el 2020 por áreas geográficas. 


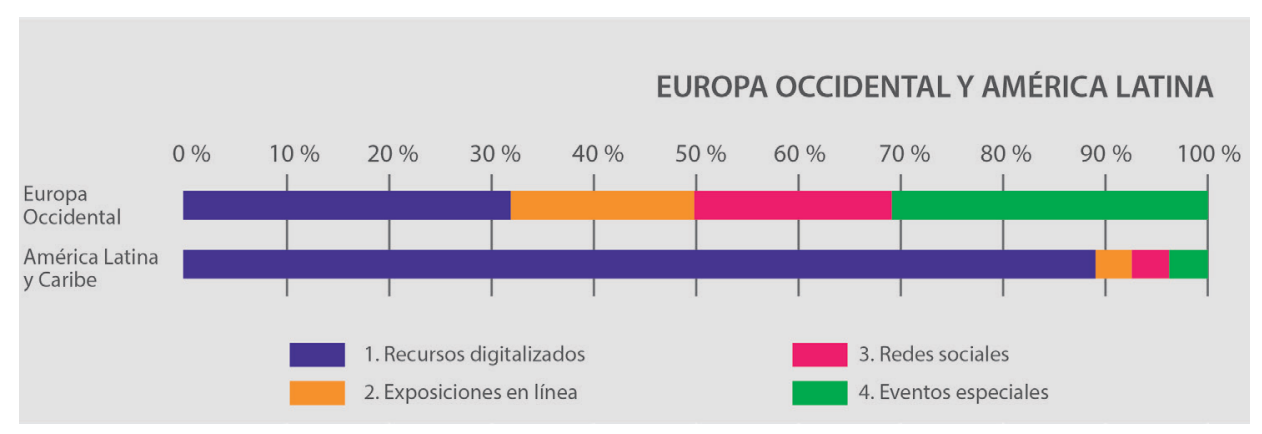

Figura 2. Cambios en las actividades digitales

Fuente: Elaboración propia con base en el Informe UNESCO (2020b)

A continuación, se definieron las subcategorías que fueron aplicadas al análisis de contenido cuantitativo. A fin de integrar los indicadores de los informes de la UNESCO, el ICOM y del NEMO, se creó una matriz de análisis para evaluar el contenido publicado por los museos (véase la tabla 1). Esta contempla las estrategias digitales implementadas por los museos teniendo en cuenta una doble temporalidad "antes del COVID-19" (recursos existentes antes de la llegada de la pandemia) y "pos-COVID-19" (aquellas que se implementaron tras la llegada del virus y los estados de alarma y excepción de los respectivos países).

Tabla 1

Distribución de tipos de respuesta numérica

\begin{tabular}{|c|c|c|c|c|}
\hline \multicolumn{2}{|c|}{ Categoría } & \multicolumn{2}{|r|}{ Subcategorías } & \multirow{5}{*}{$\begin{array}{l}\text { Detalle } \\
\text { Herramientas para la virtualidad del } \\
\text { museo: recorridos virtuales, catálogos, } \\
\text { imágenes de piezas, uso del 3D, vistas } \\
\text { 360, etcétera }\end{array}$} \\
\hline \multirow[t]{4}{*}{ RV-1 } & \multirow{4}{*}{$\begin{array}{l}\text { Recursos } \\
\text { virtuales } \\
\text { existentes }\end{array}$} & 1 & Museo en línea (recorrido virtual) & \\
\hline & & 2 & $\begin{array}{l}\text { Colección en línea (catálogos, } \\
\text { imágenes de piezas, etcétera) }\end{array}$ & \\
\hline & & 3 & Visualización 3D & \\
\hline & & 4 & Visitas 360 & \\
\hline RS-1 & $\begin{array}{l}\text { Redes } \\
\text { sociales } \\
\text { existentes }\end{array}$ & 5 & $\begin{array}{l}\text { Acciones de información, } \\
\text { promoción de campañas y } \\
\text { actividades }\end{array}$ & $\begin{array}{l}\text { Contenidos orientados al contacto } \\
\text { con el público en Facebook, Twitter, } \\
\text { Instagram, Tik-Tok }\end{array}$ \\
\hline \multirow[t]{4}{*}{ AD-1 } & \multirow{4}{*}{$\begin{array}{l}\text { Actividades } \\
\text { digitales } \\
\text { existentes }\end{array}$} & 6 & $\begin{array}{l}\text { Eventos científicos o culturales } \\
\text { en línea }\end{array}$ & $\begin{array}{l}\text { A través de plataformas de streaming: } \\
\text { Vimeo, Zoom, YouTube }\end{array}$ \\
\hline & & 7 & Publicaciones especializadas & Libros temáticos e información cultural \\
\hline & & 8 & Publicaciones informativas & $\begin{array}{l}\text { Guías, rutas culturales, material para } \\
\text { niños, etcétera }\end{array}$ \\
\hline & & 9 & $\begin{array}{l}\text { Emisiones de audio con contenido } \\
\text { temático para descarga }\end{array}$ & $\begin{array}{l}\text { Podcast: iVoxx, Soundcloud, Spreaker, } \\
\text { etcétera }\end{array}$ \\
\hline
\end{tabular}




\begin{tabular}{|c|c|c|c|c|}
\hline & & 10 & Pruebas, concursos, sorteos & $\begin{array}{l}\text { Por distintos canales: redes } \\
\text { sociales: página web, aplicación }\end{array}$ \\
\hline & & 11 & Comunicación institucional & $\begin{array}{l}\text { Boletines, mailing, newsletter, } \\
\text { etcétera }\end{array}$ \\
\hline & & 12 & Eventos científicos en vivo & $\begin{array}{l}\text { Transmisión en línea o en diferido } \\
\text { de actividades presenciales }\end{array}$ \\
\hline & & 13 & $\begin{array}{l}\text { Eventos culturales en vivo/ } \\
\text { presenciales }\end{array}$ & $\begin{array}{l}\text { Transmisión en línea o en diferido } \\
\text { de actividades presenciales }\end{array}$ \\
\hline & & 14 & Aprendizaje en línea & Cursos en línea, masterclass \\
\hline$A E-1$ & Actividades & 15 & Medidas sanitarias & Difusión y promoción de acciones \\
\hline & $\begin{array}{l}\text { especiales } \\
\text { COVID-19 }\end{array}$ & 16 & Actividades solidarias & $\begin{array}{l}\text { e iniciativas orientadas a combatir } \\
\text { la pandemia }\end{array}$ \\
\hline & & 17 & Actividades culturales/artísticas & \\
\hline RV-2 & $\begin{array}{l}\text { Recursos } \\
\text { virtuales } \\
\text { implementados }\end{array}$ & 18 & $\begin{array}{l}\text { Actualizaciones y nuevas } \\
\text { inclusiones a museo en línea } \\
\text { (recorrido virtual) }\end{array}$ & $\begin{array}{l}\text { Herramientas para la virtualidad } \\
\text { del museo: recorridos virtuales, } \\
\text { catálogos, imágenes de piezas, }\end{array}$ \\
\hline & & 19 & $\begin{array}{l}\text { Creación o ampliación de la } \\
\text { colección en línea (catálogos, } \\
\text { imágenes de piezas, etcétera) }\end{array}$ & uso del 3D, vistas 360, etcétera \\
\hline & & 20 & $\begin{array}{l}\text { Creación o ampliación de } \\
\text { visualizaciones 3D }\end{array}$ & \\
\hline & & 21 & Creación o ampliación de visitas 360 & \\
\hline RS-2 & $\begin{array}{l}\text { Actividades en } \\
\text { redes sociales } \\
\text { implementadas }\end{array}$ & 22 & $\begin{array}{l}\text { Acciones de información, promoción } \\
\text { de campañas y actividades }\end{array}$ & $\begin{array}{l}\text { Contenidos orientados al contacto } \\
\text { con el público en Facebook, } \\
\text { Twitter, Instagram, Tik-Tok }\end{array}$ \\
\hline$A D-2$ & $\begin{array}{l}\text { Actividades } \\
\text { digitales }\end{array}$ & 23 & $\begin{array}{l}\text { Eventos científicos o culturales en } \\
\text { línea }\end{array}$ & $\begin{array}{l}\text { A través de plataformas de } \\
\text { streaming: Vimeo, Zoom, YouTube }\end{array}$ \\
\hline & implementadas & 24 & Nuevas publicaciones & $\begin{array}{l}\text { Libros temáticos e información } \\
\text { cultural }\end{array}$ \\
\hline & & 25 & Nuevas publicaciones & $\begin{array}{l}\text { Guías, rutas culturales, material } \\
\text { para niños, etcétera }\end{array}$ \\
\hline & & 26 & $\begin{array}{l}\text { Nuevas emisiones de audio con } \\
\text { contenido temático para descarga }\end{array}$ & $\begin{array}{l}\text { Podcast: iVoxx, Soundcloud, } \\
\text { Spreaker, etcétera }\end{array}$ \\
\hline & & 27 & Nuevas pruebas, concursos, sorteos & $\begin{array}{l}\text { Por distintos canales: redes } \\
\text { sociales, página web, aplicación }\end{array}$ \\
\hline & & 28 & Comunicación institucional & $\begin{array}{l}\text { Boletines, mailing, newsletter, } \\
\text { etcétera }\end{array}$ \\
\hline & & 29 & Nuevos eventos científicos en vivo & $\begin{array}{l}\text { Transmisión en línea o en diferido } \\
\text { de actividades presenciales }\end{array}$ \\
\hline & & 30 & $\begin{array}{l}\text { Nuevos eventos culturales en vivo/ } \\
\text { presenciales }\end{array}$ & $\begin{array}{l}\text { Transmisión en línea o en diferido } \\
\text { de actividades presenciales }\end{array}$ \\
\hline & & 31 & Aprendizaje en línea & Cursos en línea, masterclass \\
\hline
\end{tabular}


(continuación)

\begin{tabular}{llll}
\hline ED-2 $\begin{array}{lll}\text { Extensiones } \\
\text { digitales }\end{array}$ & 32 & Aplicaciones \\
implementadas & 33 & Radio & $\begin{array}{l}\text { Herramientas concebidas como } \\
\text { respuesta a la pandemia para } \\
\text { información, difusión, ventas, } \\
\text { etcétera }\end{array}$ \\
\hline
\end{tabular}

Elaboración propia

Las categorías de índole comparativa tienden a contrastar la situación general de los museos antes de la pandemia con la realidad vivida durante el periodo de la crisis sanitaria internacional. Las subcategorías de análisis, por su parte, fueron conformadas sobre la base de las estrategias implementadas por las instituciones culturales a lo largo del periodo de estudio.

Finalmente, el trabajo cuantitativo incorporó la variable de estudio "área de intervención", en la cual se clasificaron las tácticas empleadas por los museos con base en los cuatro pilares considerados por la UNESCO: la "comunicación" (tanto propia como coordinada con otras instituciones), la "educación" (eventos formativos o de divulgación pedagógica), la "preservación" del patrimonio cultural y, finalmente, los tópicos ligados a la "investigación" de cuestiones artísticas y patrimoniales. Dichas áreas fueron clasificadas como prácticas "primarias" o "secundarias", teniendo en cuenta que las tácticas pudieron contener más de un área referencial al momento de clasificación de la información.

La selección de la muestra siguió criterios temporales y geográficos en virtud del objeto de estudio. Los primeros respondieron a un muestreo no probabilístico por conveniencia, incluyéndose todas las acciones/estrategias de difusión y promoción realizadas por los museos durante un año en sus sitios de internet (del 15 de abril del 2020 hasta el 15 de abril del 2021), tiempo en que los países se encontraban en estado de emergencia y con restricciones de movilidad.

Los museos ecuatorianos que forman parte de este trabajo siguieron el criterio de conveniencia en relación con la información proporcionada al momento de la recogida de datos. Dos de ellos pertenecen a la costa (el Museo del Bombero Ecuatoriano y el Museo Antropológico y de Arte Contemporáneo), y cuatro a la sierra (el Museo de la Catedral Vieja, el Museo de las Artes Populares de América, el Museo Abya Yala y el Museo Centro de Arte de Quito). En lo que concierne a los españoles, el trabajo contó con el análisis de los cinco de gran relevancia, de los cuales tres se emplazan en la capital. Los museos nacionales ubicados en Madrid (Museo Nacional del Prado, el Museo Nacional ThyssenBornemisza y el Museo Nacional Centro de Arte Reina Sofía). La muestra se completó con el análisis de las actividades del Museo Picasso de Málaga y del Museo Van Gogh. En el caso peruano, el trabajo se delimitó a once museos de Lima ciudad capital, en la medida que tal selección, además de asegurar oportunidad, constancia y variedad de información durante la recogida de los datos, ofrece la posibilidad de explorar las 
acciones de instituciones tanto privadas como estatales, y contrastar sus oportunidades y limitaciones.

Tabla 2

Corpus de estudio: selección de museos objeto de análisis

\begin{tabular}{|c|c|c|}
\hline \multirow[t]{6}{*}{ Ecuador } & EC-ABY & Museo Abya Yala \\
\hline & EC-CAC & Museo Centro de Arte Contemporáneo \\
\hline & EC-CID & Museo de las Artes Populares de América \\
\hline & EC-MAC & Museo Antropológico y de Arte Contemporáneo, MAAC \\
\hline & EC-MBE & Museo del Bombero Ecuatoriano \\
\hline & EC-MCV & Museo de la Catedral Vieja \\
\hline \multirow[t]{5}{*}{ España } & ES-PIC & Museo Picasso de Málaga \\
\hline & ES-THI & Museo Nacional Thyssen-Bornemisza \\
\hline & ES-MPR & Museo Nacional del Prado \\
\hline & ES-RES & Museo Nacional Centro de Arte Reina Sofía \\
\hline & ES-VAG & Museo Van Gogh Alive en España \\
\hline \multirow[t]{11}{*}{ Perú } & PER-AAH & Museo Nacional de Arqueología, Antropología e Historia del Perú \\
\hline & PER-AMA & Museo Textil Precolombino AMANO \\
\hline & PER-CUL & Museo de la Cultura Peruana \\
\hline & PER-HNA & Museo de Historia Natural UNMSM \\
\hline & PER-ITA & Museo de Arte Italiano \\
\hline & PER-LAR & Museo Larco \\
\hline & PER-MAC & Museo de Arte Contemporáneo \\
\hline & PER-MAL & Museo de Arte de Lima \\
\hline & PER-MIN & Museo de Minerales Andrés del Castillo \\
\hline & PER-OSM & Museo Pedro de Osma \\
\hline & PER-NAC & Museo de la Nación \\
\hline
\end{tabular}

Elaboración propia

\section{Análisis de datos}

Tras la colecta del cuerpo de estudio, un total de (número = 843 acciones) fueron clasificadas manualmente y luego se exportaron al formato Excel. Después, se las sometió al análisis de las variables definidas en la tabla 1. Acto seguido, se ejecutó el análisis estadístico descriptivo utilizando el programa R (R Project, 2020). Los resultados se produjeron empleando el paquete "ggplot2" (Wickham, 2016). 


\section{RESULTADOS Y DISCUSIONES}

En lo relativo a las prácticas y estrategias de difusión cultural empleadas por los museos, se comprueba (en adecuación a los referentes supranacionales) que las actividades virtuales ligadas al arte y la cultura estaban presentes antes de la llegada de la pandemia. En este sentido, como se observa en la figura 3, tanto en Ecuador como en España y en el Perú las acciones digitales fueron consideradas como estrategias principales para acercarse a las audiencias ante la crisis sanitaria.

La data recogida en los tres países muestra una vocación por mantener el contacto con la comunidad y seguir cumpliendo con las áreas de acción sugeridas por la UNESCO. Los distintos recursos desplegados dan cuenta de esfuerzos orientados a la comunicación, la educación, la investigación y la preservación, en ese orden, si nos guiamos por el número de acciones en esos rubros que pudieron verificarse en los portales digitales de los museos. El análisis exime, por tanto, empeños o trabajos en esas áreas no evidenciadas o registradas en los canales de observación definidos para este trabajo.

No obstante, si bien se registraron porcentajes diferentes, se cotejaron dos realidades:

Por un lado, en el escenario europeo, se comprueba la información proporcionada por los tres informes internacionales, así como por los resultados nacionales enunciados con anterioridad. Si bien en Europa existía una gran cantidad de contenido digitalizado, los museos aprovecharon tales circunstancias para potenciar y reforzar su virtualidad, motivo por el cual el porcentaje de estrategias de difusión "después del COVID-19" es relativamente bajo $(25,6 \%)$ en función de las actividades previas al estado de alarma. Todas las acciones implementadas desde los cinco museos censados españoles tendieron en esta línea de acción (74,4 \%).

Por otro lado, la realidad latinoamericana (fundamentalmente el caso ecuatoriano) demostró una fuerte labor en términos de digitalización de colecciones y estrategias de difusión virtuales antes de la pandemia del virus SARS-CoV-2. Las estrategias implementadas por los gestores culturales del Ecuador indican que la pandemia fue el punto de partida de sobreproducción de contenido virtual. Con el objetivo de incrementar y de hacer más accesible la cultura a la sociedad, las actividades y la difusión de contenido cultural de todo tipo aumentaron (83,5\%). De esta manera, los museos ecuatorianos se involucraron en el proceso de construcción y comunicación de eventos virtuales de carácter social. 


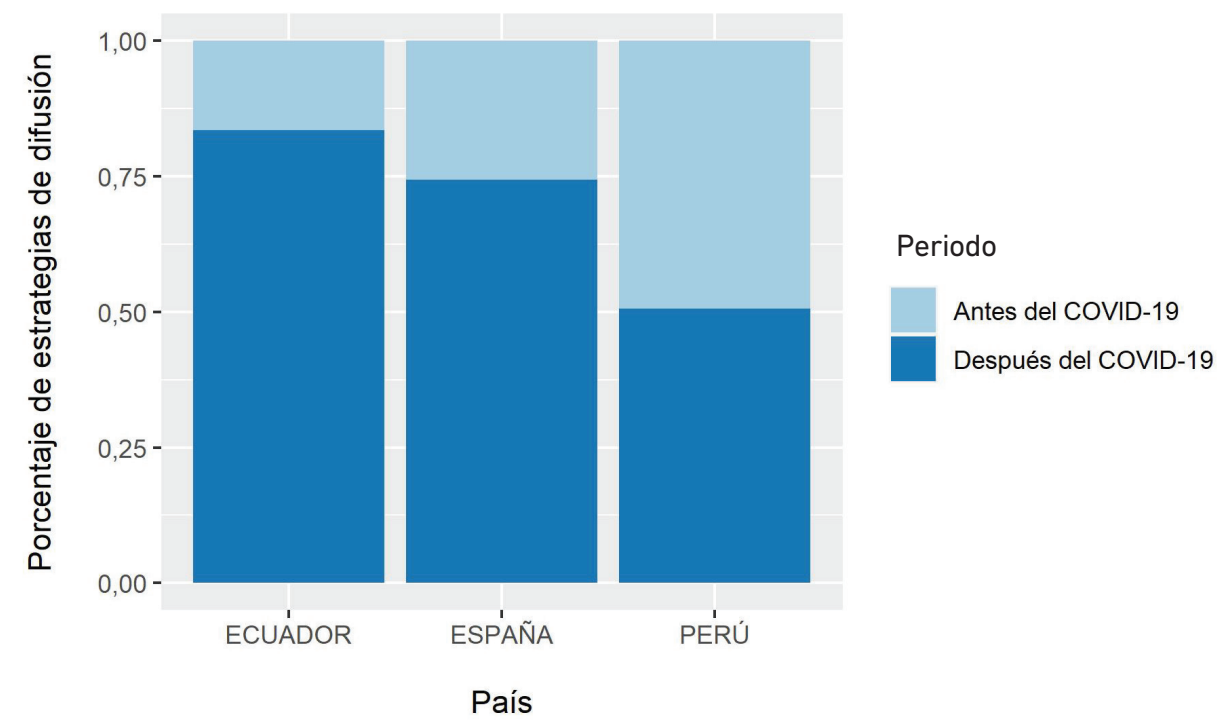

Figura 3. Comparativa de estrategias digitales empleadas por país

\section{Elaboración propia}

Desde el escenario peruano se asiste a una paridad en términos de difusión de estrategias digitales. Mientras que casi la mitad de las estrategias comunicacionales ya formaban parte de la agenda de los museos $(49,4 \%)$, el resto de tácticas de difusión siguieron idénticos lineamientos y aumentaron ligeramente tras la etapa de confinamiento $(50,6 \%)$, lo que significa un aprovechamiento de la capacidad instalada antes de la pandemia, pero con poca diversificación y novedad en cuanto a contenido.

Si se reduce el estudio de la muestra al escenario gestado por cada museo, se advierten las siguientes realidades:

La preeminencia de las actividades digitales pos-COVID-19 (aquellas implementadas tras la aparición de la pandemia en los países, con fechas diferentes en función de las agendas estatales). Cabe destacar que el término "pos-COVID-19" está en íntima relación con el uso que las autoridades hicieron de él para referirse a la posdeclaración de emergencia sanitaria. De manera contraria, "antes del COVID-19" viene a englobar las estrategias digitales implementadas antes de la llegada del virus SARS-CoV-2.

La gran mayoría de los museos - con excepción del Van Gogh Alive (VAN-España) y del Museo de la Nación (NAC-Perú) - centran su accionar en las prácticas digitales durante el periodo de confinamiento y no antes (véase la figura 4). El caso puntual del Museo Van Gogh (VAN) resulta peculiar, ya que este decide cerrar tras la medida del estado de alarma anunciada por el Gobierno. La presencialidad se retoma con la apertura definitiva de las salas culturales, situación por la cual las estrategias recabadas 
pertenecen al periodo "antes del COVID-19". En lo que concierne al Museo de la Nación (NAC), el cierre temporal decretado en marzo del 2020 a raíz de la declaración del estado de emergencia continúa mientras se redacta el presente artículo.

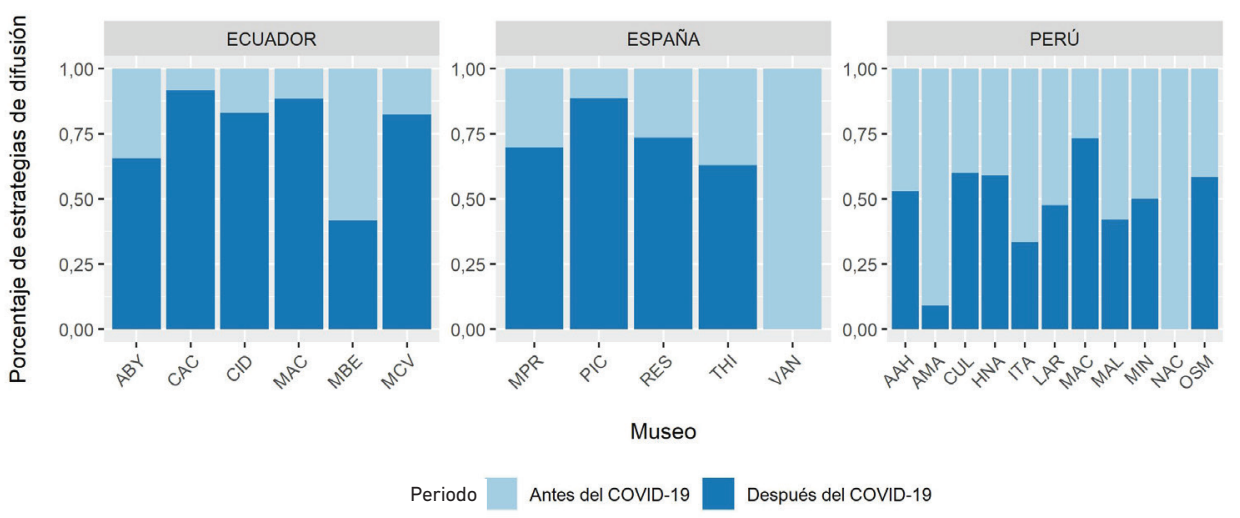

Figura 4. Estrategias digitales de difusión generadas por los museos

Elaboración propia

En el caso español, se observa igualmente un fuerte programa digital desde el Museo Picasso de Málaga (PIC), así como por parte de los madrileños Reina Sofía (RES) y El Prado (PRA), quienes obtuvieron una gran repercusión en los medios tras las medidas tomadas una vez decretado el estado de alarma.

Desde Ecuador se constata que el Museo del Bombero Ecuatoriano (MBE) posee menores índices de inserción comunicacionales. Se trata de la única institución en el país que guarda memoria de un servicio sin relacionarse con el quehacer artístico-cultural. Su fortaleza son las visitas a las instituciones educativas, recorridos in situ y las capacitaciones formativas presenciales, motivo por el cual las actividades generadas durante la pandemia fueron más limitadas frente al resto de los museos.

Finalmente, en el caso peruano, los museos privados aventajan a los públicos en actividades digitales. Sus iniciativas no solo son más numerosas, sino que fueron capaces de ampliar la virtualidad existente antes de la pandemia, aunque la mayoría de sus contenidos depende mucho de las posibilidades de las redes sociales. En este sentido, los museos del Estado permanecen en piloto automático, gestionando en el espacio digital las herramientas y dinámicas previas a la emergencia sanitaria.

\section{Tipos de estrategias digitales en función de las categorías de estudio}

Tras restringir aún más el universo de estudio, y tomando en consideración las estrategias de difusión museística generadas tras los respectivos estados de alarma y consecuentes 
confinamientos, se pudo detectar que tanto las actividades digitales implementadas (AD) como las actividades en redes sociales implementadas (RS) fueron los recursos más referenciados y explotados. Esto no hace sino confirmar los resultados que ya señalaban los informes supranacionales. En este sentido, en la figura 5 se observa las tendencias que se describen a continuación.

Por un lado, se constata que los recursos virtuales implementados tras el inicio de la pandemia (RV-2) fueron las estrategias menos sobresalientes. Con excepción del Museo Antropológico y de Arte Contemporáneo (MAC-8,06 \%) y del Museo Centro de Arte Contemporáneo (1,15\%) ; así como del museo Thyssen (THI-12,82 \%), el Picasso de Málaga (PIC-5,94 \%) y El Prado (MPR-1,99 \%) en España, la creación de nuevos recursos virtuales (exposiciones temporales, nuevos recorridos virtuales, apertura de nuevos canales en las redes sociales, entre otros tópicos) no adquirió gran representación dentro de la muestra de estudio, ya que el contenido difundido virtualmente contaba con recursos digitales reconocidos y de gran popularidad por parte de sus audiencias interactivas.

En el caso peruano, la tendencia fue un tanto más representativa, considerando que seis de las once instituciones analizadas implementaron recursos digitales nuevos. Buena parte de las novedades publicadas por los museos Larco (LAR) y de Arte Contemporáneo (MAC) fueron resultado de trabajos que venían desarrollándose meses atrás, de modo que la pandemia aceleró su desarrollo o precipitó su oportuno estreno (la implementación de recursos virtuales venía trabajándose como un esfuerzo constante en los últimos años).

Por otro lado, con relación a las extensiones digitales implementadas por los museos (ED-2), la gran mayoría no se embarcó en la generación de proyectos a gran escala creando aplicaciones, radios o web series, por ejemplo. En Ecuador los valores restan a cero en todas las instituciones culturales analizadas.

En España, sin embargo, desde el Museo Nacional del Prado (MPR) se generó un importante contenido en la materia (9,8\%), apostando la institución por cuatro iniciativas de gran impacto: se lanzó la primera tienda de museo en Amazon.es que impulsó la estrategia de mercado en línea como herramienta de financiación complementaria. Se implementó la creación de una aplicación junto a Samsung que permite visitar "El Tesoro del Delfín" de forma virtual. Se publicó, además, la primera guía oficial para smartphones Android e iOS, una iniciativa que permite a los visitantes conocer más de cuatrocientas obras. Finalmente, se generó el programa "El Prado para Todos" junto a Samsung con el fin de impulsar el acceso a la cultura a personas con necesidades específicas. El Museo Picasso de Málaga (MPM) no se quedó atrás $(0,99 \%$ y anunció la implementación de una nueva aplicación que incluía una audioguía de la colección permanente en diez idiomas. Por último, el Museo Nacional Centro de Arte Reina Sofía (MRE) incorporó macroiniciativas (1,9\%). Se trató del lanzamiento del espacio virtual Gigapixel, en colaboración, con 
Telefónica que permite al internauta explorar obras de la colección con resolución ultraHD. De la misma manera, el MRE amplió la web Repensar Guernica, la cual se completó con más de doscientos documentos, entrevistas inéditas y la sección "Contra-archivos", publicándose en paralelo un estudio de materiales creado por diferentes profesionales e investigadores en torno al cuadro.

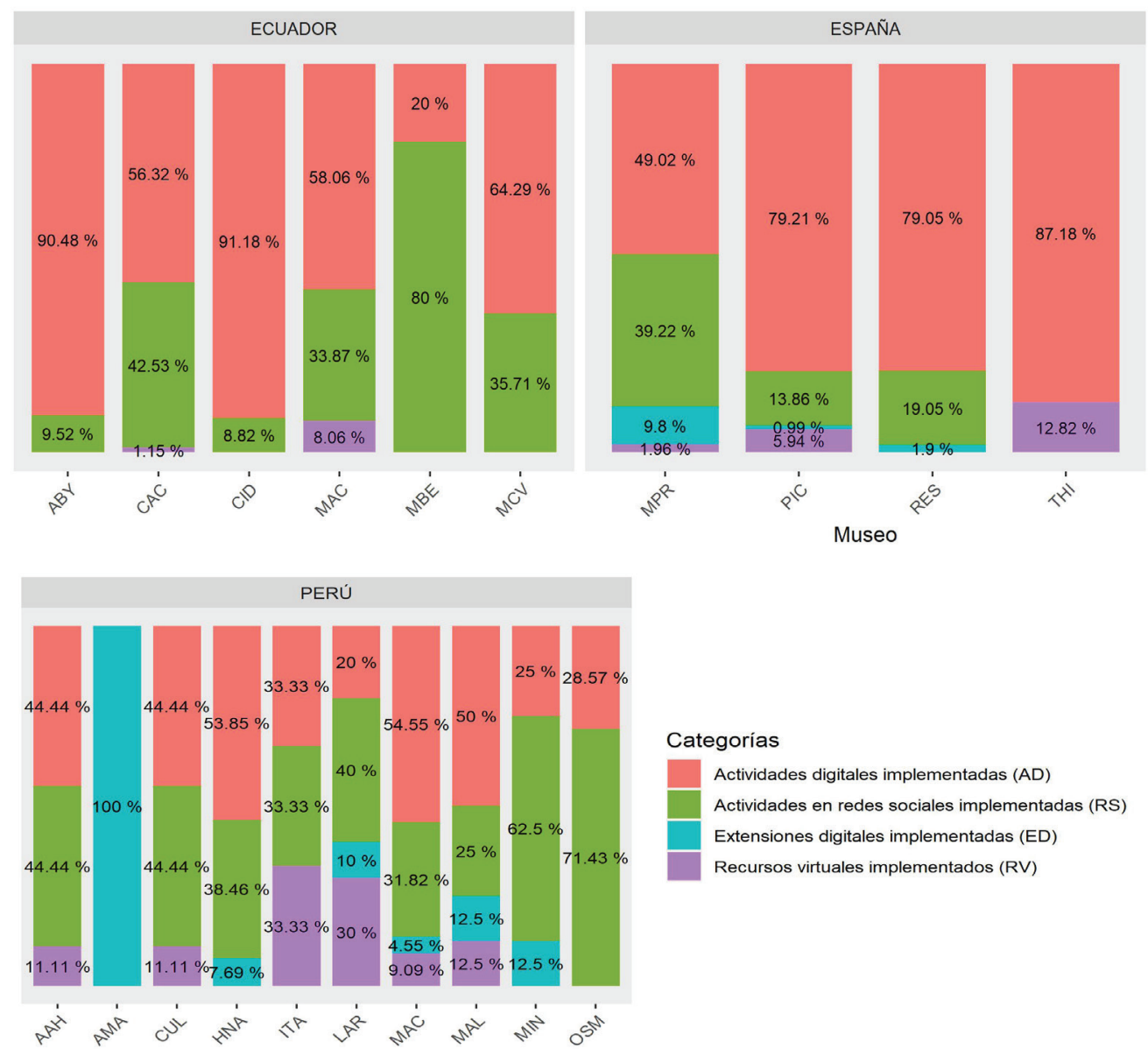

Figura 5. Categorías implementadas por los museos tras el confinamiento

\section{Elaboración propia}

Las extensiones digitales del Perú se desplegaron en dos frentes. Unas orientadas a la generación de nuevas plataformas de difusión de contenidos (entre las que destacan la miniserie web desarrollada por el Museo Larco [LAR] sobre el antiguo Perú y los podcasts del Museo de Arte Contemporáneo[MAC] en plataformas como Spotify, 
Apple y Google Podcast), y otras destinadas a la generación de ingresos alternativos, básicamente nuevos canales y aplicaciones que promueven y facilitan las ventas que antes se daban en la tiendas de los museos. El Museo de Minería (MIN), el de Arte Textil Precolombino (AMA) y el de Arte Contemporáneo (MAC) han sido los más dinámicos en este sentido.

Sin duda, la paridad entre las actividades digitales implementadas (AD) y las actividades en redes sociales implementadas (RS) son los elementos que más llamaron la atención en los tres casos de estudio. De manera genérica puede decirse que las tácticas efectuadas desde las redes sociales dominaron el panorama digital implementado en los museos del Perú. La situación inversa se registró en el caso de los museos ecuatorianos y españoles. Desde el escenario español, el contenido producido y divulgado desde la página web de los propios museos cobra mayor protagonismo. La misma situación se replica en Ecuador, con excepción del Museo del Bombero Ecuatoriano (MBE), quien supera la media con $80 \%$ de estrategias implementadas en las redes sociales. El aumento radica en la presencialidad de las actividades del museo antes de la llegada de la pandemia, por lo que se tuvo que aplicar de manera urgente una presencia digital en las redes sociales.

En cuanto a las subcategorías de análisis estudiadas, las estrategias primordiales generadas desde los tres países siguen tendencias similares con ciertos matices divergentes (véase la figura 6). Se comprueba cómo las prácticas digitales llevadas a cabo desde la declaración del estado de emergencia hasta el 15 de abril del 2021 se encuadran primordialmente en las subcategorías de análisis "Redes sociales implementadas desde Facebook, Twitter, Instagram y Tik-Tok" (subcategoría 22) y por medio de los "Canales de streaming: Vimeo, Zoom y YouTube" (subcategoría 23).

De la misma manera se evidencia que estas actividades digitales ocupan un espacio importante en la producción de contenido de orden comunicacional, entre las que resaltan los "Eventos científicos digitales en vivo, en combinación con la presencialidad" (subcategoría 29), los "Eventos culturales digitales en vivo y mixtos" (subcategoría 30), así como las "Actividades de aprendizaje en línea" (subcategoría 31).

En segunda instancia, se verifica que las prácticas secundarias iniciadas por los museos se corresponden complementariamente con las primarias. Esta información viene a confirmar la importancia acordada a la comunicación digital durante el toque de queda y el confinamiento, y hasta el periodo de tiempo que culminó el 15 de abril del 2021. Si bien los informes internacionales adelantaban esta información de forma generalista y predictiva, el análisis pormenorizado de los 21 museos retrata el panorama en tres países con realidades similares. 


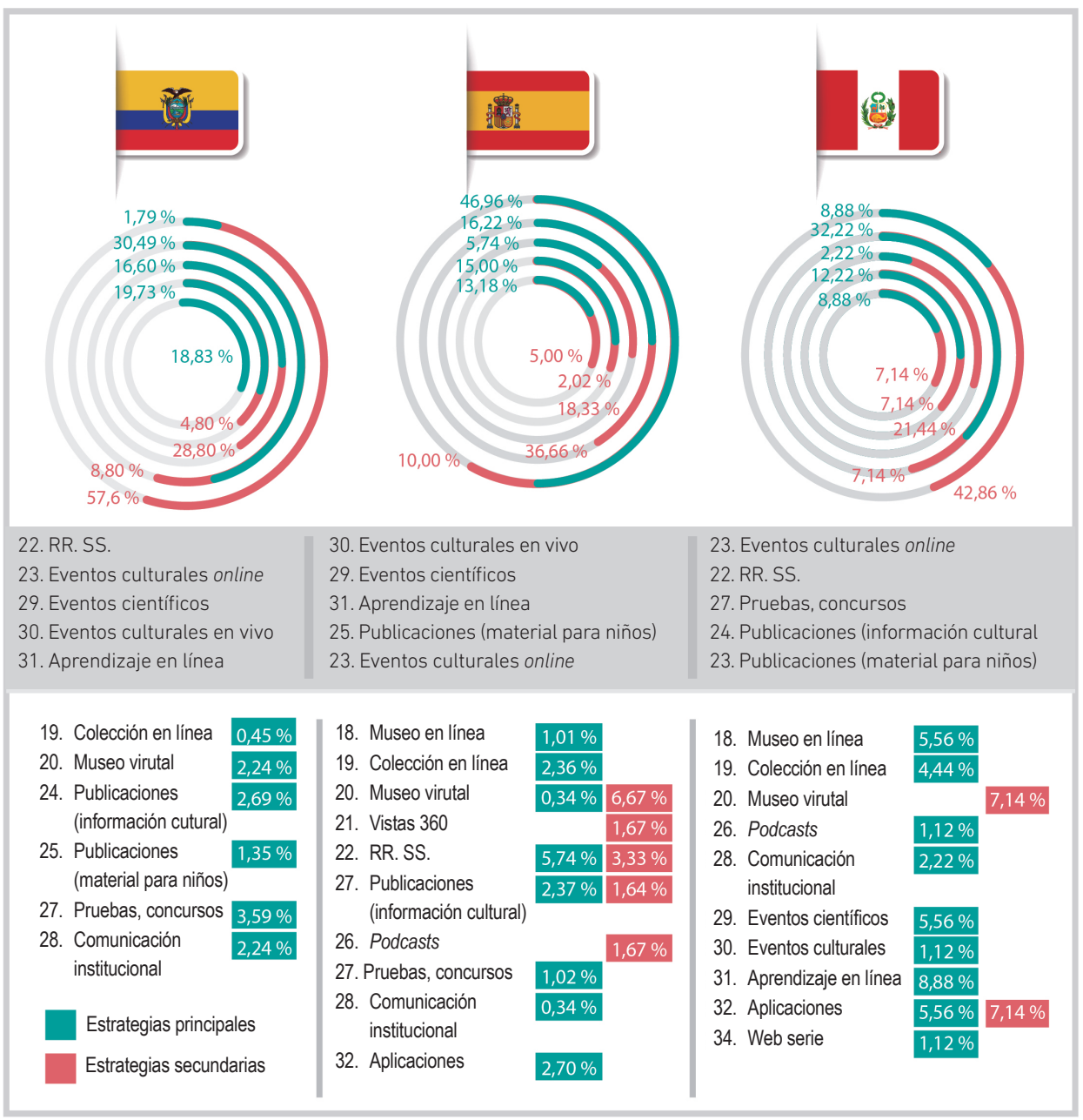

Figura 6. Subcategorías implementadas por los museos luego del estado de alarma Elaboración propia

\section{Estrategias digitales y áreas de trabajo de la UNESCO}

Anclados en las cuatro funciones esenciales de los museos (definidas en la "Recomendación relativa a la protección y promoción de los museos, su diversidad y su función en la sociedad" de la UNESCO), se ha podido evidenciar la fuerte presencia de la función comunicativa y educativa empleada en los museos de Ecuador, España y Perú. Los tres pusieron en efecto estrategias digitales de comunicación y de acercamiento a los públicos durante y después del periodo de confinamiento, al menos hasta el 15 de abril del 2021 que es cuando se concluye el trabajo de observación de campo. En este 
sentido, como recoge la figura 7, las aproximaciones de corte "comunicacional" obtuvieron más relevancia en todos los casos de estudio de España y Perú, y en cuatro de los seis museos ecuatorianos: Abya Yala (ABY), Centro de Arte Contemporáneo de Quito (CAC), Antropológico y de Arte Contemporáneo (MAC) y Catedral Vieja de Cuenca (MCV).

De manera muy poco representativa, se constata que las estrategias secundarias con temática comunicacional no logran superar otras áreas de acción al adicionar el contenido supletorio. La acción desarrollada desde el Museo Nacional ThyssenBornemisza (THI) da cuenta, en este sentido, de cómo un puñado de estrategias secundarias llegan a inclinar la balanza en contra de las tácticas educativas y en favor de las comunicacionales.

En lo que concierne a las áreas de acción ligadas a la "educación", no es de extrañar que las actividades vinculadas a la instrucción, a la formación profesional y al aprendizaje de habilidades educativas y pedagógicas se posicionarán como segunda política de acción en cuanto a difusión (véase la figura 7). A este respecto, las gestiones implementadas desde España, concretamente desde el Museo Picasso de Málaga (MPIC) y del Museo Nacional Thyssen-Bornemisza (THI) cobran mayor presencia de manera secundaria y no principal, como en los demás casos. Asimismo, el modelo seguido desde los museos peruanos releva idénticas acciones con excepción de los museos de Arqueología, Antropología e Historia (AAH), el Museo Larco (LAR), el de Cultura Peruana (CUL), el Museo de Arte de Lima (MAL) y el Museo Pedro de Osma (OSM), donde las tácticas secundarias sobrepasan las principales, sin afectar los resultados finales.

Ecuador
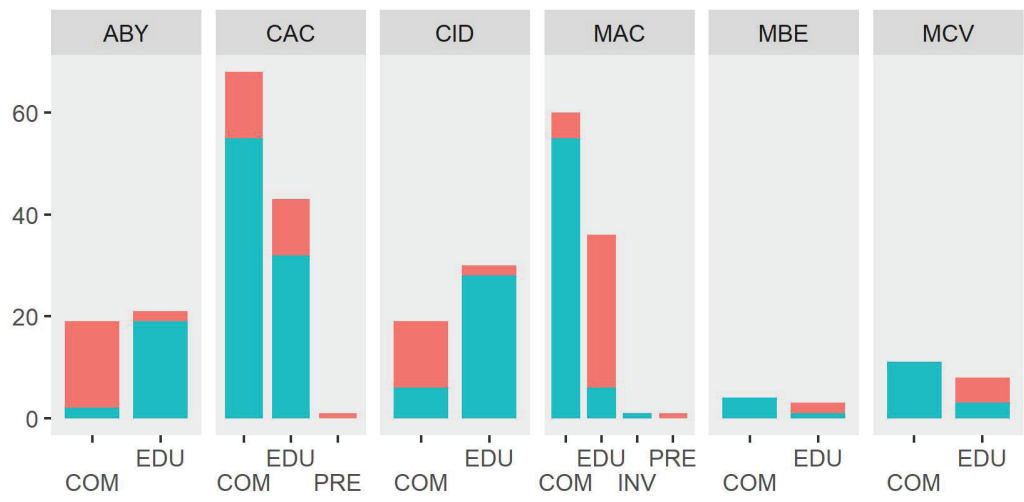

Subcategorías 

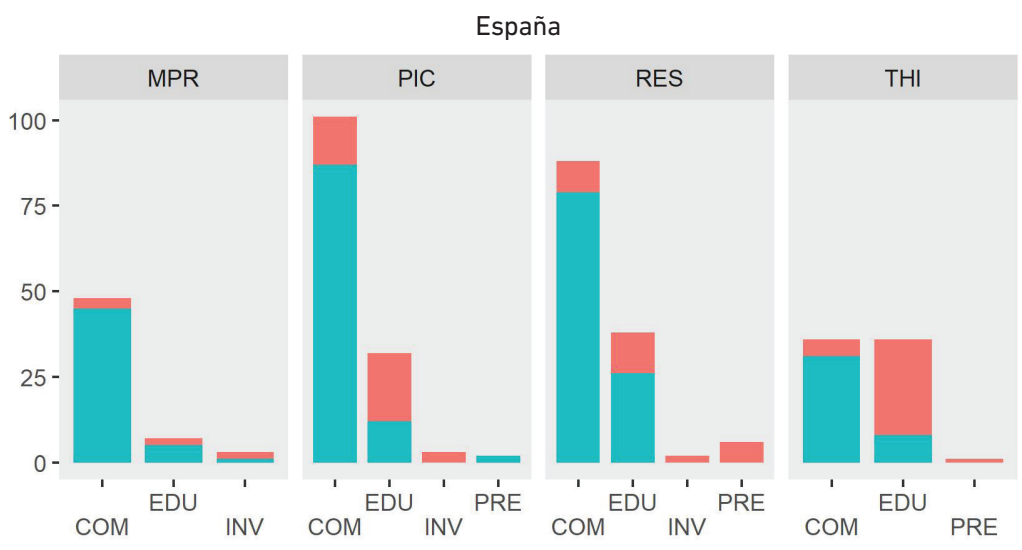

Subcategorías

Área secundaria Área principal

Perú
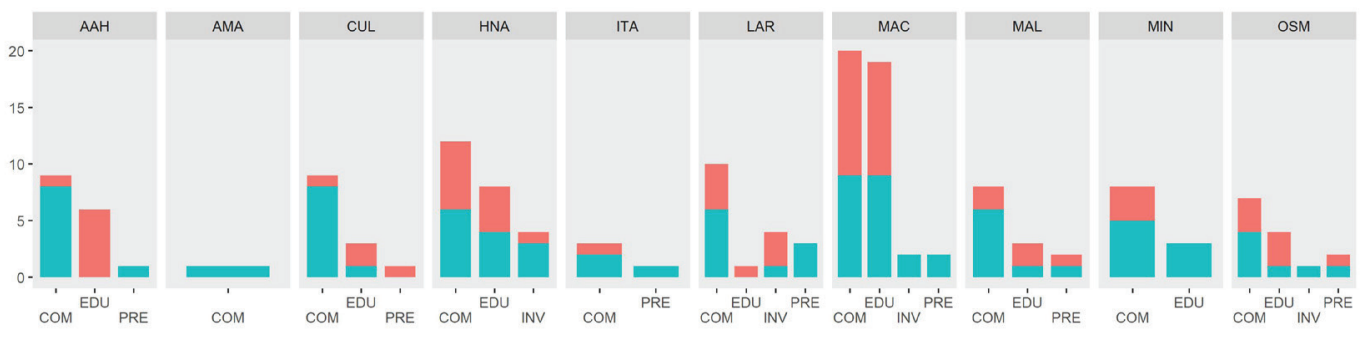

Subcategorias

Área secundaria

Área principal

Figura 7. Áreas de acción UNESCO y estrategias de comunicación digitales

Elaboración propia

El modelo ejecutado por algunas instituciones culturales de Ecuador rompe el esquema descrito con anterioridad. A tal efecto, desde el Museo Abya Yala (ABY) y Museo de las Artes Populares de América (CID), priman las áreas generales de acción por sobre las comunicacionales, aproximándose en equidad a otras instituciones como el Museo del Bombero Ecuatoriano (MBE) y el Museo de la Catedral Vieja de Cuenca (MCV), desde donde los enunciados educativos alcanzan gran importancia, pero en segunda medida.

Los tópicos que comprenden iniciativas vinculadas con la adquisición y gestión de colecciones, la conservación preventiva, así como la seguridad de sus piezas en exhibición y en depósito definidas en el "Área Preservación" no son sistematizados de forma recurrente desde los tres países. En relación con ello, se evidenció un ínfimo porcentaje 
de museos que aprovecharon la pandemia para informar y aplicar estrategias digitales en este plano de acción. En el caso español, tres de los cinco museos aplicaron políticas sobre la preservación, primando el carácter secundario y no el primordial al momento de la difusión. La misma situación se registra en Ecuador, donde dos de los seis museos registran actividades de preservación de manera complementaria. Los museos peruanos, por su parte, son los más interesados en cuestiones referentes a la conservación. Especialmente, el Museo de Arqueología, Antropología e Historia (AAH), el Museo Larco (LAR), el de Arte Contemporáneo (MAC) y el Museo Italiano (ITA) se hacen eco de manera primordial de acciones y estrategias digitales relacionadas con la gestión de los bienes culturales. De manera secundaria, la intervención del Museo de la Cultura Peruana (CUL), el Museo de Arte de Lima (MAL) y el Museo Pedro de Osma (OSM) complementan este espectro de actuación.

Finalmente, se comprueba un interés menor en lo referente al área de "investigación". En este sentido, las estrategias de los museos orientadas hacia el estudio y la reflexión histórica de las colecciones museísticas han desaparecido por completo de la escena durante la crisis sanitaria del COVID-19, manifestándose en contadas ocasiones en un puñado de museos. Al respecto, y en función a la figura 7 se evidencia que en su mayoría este tipo de tópicos fueron abordados desde España de manera secundaria. Aunque el Museo Nacional del Prado (MPR) con su única estrategia virtual directa descubrió algunas de sus obras a través de la técnica de rayos $\mathrm{X}$. El resto de las estrategias implementadas desde el propio Prado (2), el Museo Picasso (3), así como del Reina Sofía (2), son complementarias a las estrategias de difusión de orden comunicacional.

Desde Ecuador la investigación cultural de manera principal se hace presente únicamente en el Museo Antropológico y de Arte Contemporáneo (MAC), aunque con escasa recurrencia. Esto se debe a que el accionar del gobierno central afectó el área de investigación tras una serie de recortes de presupuesto. Además, en la ciudad de Guayaquil, coincidentemente, se encuentra ubicada la Universidad de las Artes, la cual trabaja en conjunto con el MAC con la finalidad de generar más espacios de exhibición y educación cultural.

Finalmente, desde el Perú, sobre el total de once museos analizados la impronta investigadora se hace presente en cuatro oportunidades con un nivel de representatividad medio: Museo Larco (LAR), Museo de Arte Contemporáneo (MAC), Museo de Historia Natural (HNA) y Museo Pedro de Osma (OSM). En la mayoría de los casos las estrategias entabladas por los museos aplican tácticas de orden principal, que se complementan con acciones secundarias que refuerzan su énfasis en este rubro. Destaca el Museo de Historia Natural (HNA), que presentó y difundió tanto artículos de investigación académica firmados por los científicos que trabajan en el museo como publicaciones en físico y digital promovidas por la entidad con el apoyo de instituciones y fondos de cooperación internacional, como el referido al de "Las plantas comunes del bosque seco del Marañón". 


\section{CONCLUSIONES}

Este estudio exploratorio buscó entender cómo los museos de tres países -Ecuador, España y Perú- enfrentaron la pandemia mundial del COVID-19. Para tal fin, y apoyado en los informes supranacionales emitidos por la UNESCO, el ICOM y el NEMO, el análisis mixto (cuantitativo/cualitativo) evaluó las prácticas y herramientas digitales implementadas en la muestra de museos. Así, no solo se constató el valor predictivo generalista de los informes internacionales, sino que, tomando en cuenta la situación sociocultural y político-administrativa de los tres países, se advirtieron particularidades en el trabajo digital, destacando especialmente las estrategias implementadas desde redes sociales y plataformas digitales orientadas al ámbito comunicacional y educativo.

En cuanto a las prácticas de difusión de los museos ecuatorianos, españoles y peruanos, se constató que las estrategias digitales se vieron reforzadas y complementadas por nuevas iniciativas dirigidas al contacto con sus públicos. Como se ha comprobado, mientras en España (74,4 \%) y Ecuador (83,5 \%) la mayoría de las acciones posconfinamiento se ejecutaron de manera dinámica durante el periodo del COVID-19 (aumentando considerablemente en comparación con el periodo pre-COVID-19), en el Perú no se registró un gran incremento $(50,6$ \%), más bien se continuó trabajando en la virtualidad y la digitalización del contenido cultural de la misma manera como se hacía antes de la pandemia. Con base en el informe del ICOM (2020a, 2020b), se nota el esfuerzo desplegado por los grandes museos españoles y las instituciones ecuatorianas y peruanas al implementar y mejorar sus actividades digitales. En este sentido, mientras que en España se explotaron los recursos ya digitalizados y se crearon nuevas herramientas para dinamizar la cultura, en Ecuador se apostó por la creación de nuevas actividades (en muchas ocasiones implementando los recursos ya existentes y popularizados por los museos europeos). Finalmente, desde el Perú se revela un gran trabajo de digitalización aprovechando las posibilidades de las redes sociales, algo que ya se había advertido en años anteriores (Alvarado, 2018).

Tomando en cuenta el tipo de contenido producido y los recursos desplegados para llegar al público, se pudo revelar que las actividades digitales implementadas (AD) y las actividades en redes sociales implementadas (RS) fueron las más referenciadas por los tres países. Esto corrobora los resultados adelantados por los informes supranacionales, fundamentalmente en lo relativo al uso de las redes sociales y las plataformas audiovisuales, motores esenciales en la práctica difusora.

Si se consideran los indicadores señalados en el informe UNESCO (2020b) para Europa occidental y Estados Unidos, hay que decir que mientras un $20 \%$ de las estrategias se centraron en las redes sociales, otro gran $31 \%$ se dedicó a crear actividades digitales especiales para la pandemia. Tras comparar los indicadores con los recogidos para el caso español, se advierte que los museos se aventuraron en la concepción de proyectos 
proyectos a gran escala, creando aplicaciones o grandes proyectos. En ese sentido, aprovecharon los elementos ya disponibles para difundir sus estrategias de comunicación. Estas actividades estudiadas bajo la categoría extensiones digitales implementadas (ED-2) no fueron las más representativas, como sí lo fueron las actividades digitales implementadas (AD) y las actividades en redes sociales implementadas (RS), dos de las vías que más popularidad adquirieron en los medios de comunicación y en la propia audiencia que participó desde las redes.

Por su parte, los museos latinoamericanos, según el informe del ICOM (2020b), ya contaban con recursos digitalizados (88\%), situación que hizo que emprendieran en menor medida nuevas exposiciones en línea ( $4 \%$ ) y actividades especiales (4\%). Sin embargo, la presente investigación sirvió para contextualizar la situación particular del Ecuador y del Perú. A tal efecto, las actividades digitales implementadas (AD) y las actividades en redes sociales implementadas (RS) de ambos países resultaron ser más representativas que la media descrita por el informe ICOM. Se desmarcan como los elementos mejor implementados. Desde el escenario peruano, fueron las estrategias difundidas en las redes sociales las que mejor representación obtuvieron, mientras que desde Ecuador las actividades digitales puntuales creadas durante la pandemia.

Con respecto a las subcategorías, se observa un uso de las estrategias primordiales con una tendencia similar y ciertos matices divergentes. Las prácticas digitales implementadas desde el 15 de abril del 2020 y hasta el 15 de abril del 2021 se encuadraron primordialmente en las subcategorías de análisis "Redes sociales" siendo las estrategias de Facebook, Twitter, Instagram y Tik-Tok las más populares. Los "canales de streaming", como las plataformas Vimeo, Zoom y YouTube, fueron también de las actuaciones preferidas para difundir contenido cultural, educativo e informativo. Por su lado, los "Eventos científicos digitales en vivo, en combinación con la presencialidad", así como los "Eventos culturales digitales", completaron la grilla de actuación en los tres países, demostrando de esta manera que la virtualidad y la interacción fueron elementos esenciales para mantener el contacto con el arte y el patrimonio.

En lo relativo a las áreas estratégicas de gestión comunicacional (organizadas según los criterios UNESCO y definidos en la "Recomendación relativa a la protección y promoción de los museos"), se constató la fuerte y marcada presencia del carácter "comunicacional" y "educativo" de los enunciados implementados desde Ecuador, España y Perú. Estas estrategias de acercamiento a los públicos mostraron al mismo tiempo una complementariedad supletoria con las estrategias secundarias, conformando la totalidad de la muestra en ambos indicadores. La "educación" relegada a la segunda plaza, por debajo de la "comunicación", se postula como otra táctica digital inclusiva, abarcando a todos los públicos, desde niños, pasando por adolescentes, e incluyendo a adultos y jubilados. Por su parte, los asuntos ligados a la conservación preventiva (área 
de "preservación"), así como los referentes al área de "investigación", fueron los menos divulgados o evocados desde los tres países.

El presente trabajo se inscribe en un interés interdisciplinario en medir las prácticas digitales realizadas por una serie de museos de Ecuador, España y el Perú. Aquí radica una primera limitación del estudio, ya que la muestra fue considerada tomando criterios específicos para cada área geográfica. Una segunda limitación se vio determinada por el periodo de recolección de la muestra. En este sentido, teniendo en cuenta la duración de un año, el corpus de estudio fue recogido manualmente por parte de los tres investigadores. Si bien los criterios generales del vaciado de la información implicaron lineamientos generales cubiertos en los tres informes supranacionales (UNESCO, ICOM y NEMO), la subjetividad de ciertas instancias llevó a ponderar algunas estrategias en favor de prácticas primarias y secundarias, como se ha visto a lo largo de la investigación.

Finalmente, debe tenerse en cuenta que se trata de un estudio exploratorio tendiente a comparar tres universos de análisis diferentes, lo cual en cierta medida afecta la visión comparativa que se encuentra en los informes internacionales. Al respecto, el presente trabajo, así como su metodología, pueden ser replicados para analizar los efectos de la pandemia en el accionar museístico de otros países y museos. De la misma manera, otros tipos de abordajes podrían aplicarse al estudio de la muestra a fin de profundizar en ciertas estrategias desarrolladas o no gestionadas por parte de las instituciones museísticas.

\section{REFERENCIAS}

Alvarado, E. (2018). Hacia un museo sostenible: oferta y demanda de los museos y centros expositivos de Lima. Museo de la Nación. https://doi.org/10.31381/illapa. v0i15.1849

Asociación Profesional de Conservadores Restauradores de España. (2020). Impacto económico de la COVID-19 en el sector de la Conservación-Restauración. https:// bit.ly/3g49k4l

American Alliance of Museums. (2020a). 4 Ways Museums Can Successfully Leverage Digital Content and Channels During Coronavirus (COVID-19). https://bit.ly/35wvNks

American Alliance of Museums. (2020b). How Your Museum can Use Social Media during COVID-19. https://bit.ly/3gEnucN

American Alliance of Museums. (2020c). Curatorial Dreaming in the Age of COVID-19. https://bit.ly/3q7ZpOn

Asamblea Nacional del Ecuador. (2010). Código Orgánico de Organización Territorial. Organization of American States. https://bit.ly/3cZ50kX 
Ley 16/1985. Ley del Patrimonio Histórico Español. 25 de junio de 1985. Boletín Oficial del Estado. https://bit.ly/3gQwmLb

Consejo de Ministros. (14 de marzo del 2020). El Gobierno decreta el estado de alarma para hacer frente a la expansión de coronavirus COVID-19. https://bit.ly/3yLCbSe

Consejo Internacional de Museos. (2020a). Informe. Museos, profesionales de los museos. https://bit.ly/3t5WTsJ

Consejo Internacional de Museos. (2020b). Museos, profesionales de los museos y COVID19: Encuesta de seguimiento. https://bit.ly/2PNBrKR

Consejo Internacional de Museos. (2020c). Cómo comunicarse (je interactuar!) a distancia con su público. https://bit.ly/3iVGhS2

Díaz Salamanca, A. D., Moreno Romero, C. L., y Rojas, J. T. (2019). Relatos digitales museológicos en la comunicación social de la ciencia. Estrategias narrativas innovadoras para salvaguardar el patrimonio de los museos capitalinos. https://bit.ly/3yS4XiZ

Decreto Supremo 044-2020 [Presidencia del Consejo de Ministros]. Decreto Supremo que declara Estado de Emergencia Nacional por las graves circunstancias que afectan la vida de la Nación a consecuencia del brote del COVID-19. 15 de marzo del 2020. https://busquedas.elperuano.pe/normaslegales/decretosupremo-que-declara-estado-de-emergencia-nacional-po-decreto-supremon-044-2020-pcm-1864948-2/

Decreto Supremo 201-2020 [Presidencia del Consejo de Ministros]. Decreto Supremo que prorroga el Estado de Emergencia Nacional por las graves circunstancias que afectan la vida de la Nación a consecuencia de la COVID-19. 21 de diciembre del 2020. https://bit.ly/2Ug6QXW

Gobierno del Perú. Plataforma digital única del Estado Peruano. (2021). Coronavirus: medidas para enfrentar la pandemia según nivel de alerta y región. https://www. gob.pe/12365

Ibermuseos. (2018). Nuestro papel en el sector. https://bit.ly/3vnF34A

Ibermuseos. (2020). Panorama de los museos en Iberoamérica. https://bit.ly/3dZmXzi

Instituto Nacional de Patrimonio Cultural. (2020). Protocolo general de bioseguridad para prevención de contagio del COVID-19 en museos de sitio de áreas arqueológicas y paleontológicas. https://bit.ly/3wEIZj3

Ministerio de Cultura del Perú (2012). Guía de museos del Perú. https://bit.ly/3iKX1vq Ministerio de Cultura del Perú (2020). Visita virtual. https://bit.ly/2TD2QR2

Ministerio de Cultura y Deporte de España. (2020a). Anuario de Estadísticas Culturales. 
https://bit.ly/35pMDBb

Ministerio de Cultura y Deporte de España. (2020b). Planificación de medidas para la reapertura de los museos de titularidad y gestión estatal dependientes de la Dirección General de Bellas Artes. https://bit.ly/3dTZvDM

Ministerio de Cultura y Patrimonio del Ecuador. (2018). Directorio de Red Ecuatoriana de Museos 2019. https://bit.ly/3gVvSTN

Museo del Prado (2020). Casi 2 millones de usuarios visitan el Prado durante el confinamiento. https://bit.ly/3iNLkEd

Network of European Museum Organisations. (2021). Follow-up Survey on the Impact of the COVID-19 Pandemic on Museums in Europe. Final Report. https://bit.ly/3aOr50f

Observatorio de Museos de España. (2020). Los museos españoles ante la pandemia de COVID-19. https://bit.ly/2RSRTu5

Organización de las Naciones Unidas para la Educación, la Ciencia y la Cultura. (2015). Recommendation Concerning the Protection and Promotion of Museums and Collections, their Diversity and their Role in Society. https://bit.ly/3q0rg36

Organización de las Naciones Unidas para la Educación, la Ciencia y la Cultura. (2020a). Cultura y COVID-19 Impacto \& Respuesta [Issue 4]. https://bit.ly/2RwIR5H

Organización de las Naciones Unidas para la Educación, la Ciencia y la Cultura. (2020b). Rapport UNESCO. Les Musées dans le Monde face à la pandémie de COVID-19. https://bit.ly/3uH603j

Organización de las Naciones Unidas para la Educación, la Ciencia y la Cultura. (2020c). Los museos ante los desafíos de COVID-19 continúan comprometidos con las comunidades. https://bit.ly/3vDWQEN

Presidencia de Gobierno de España. (2021). La COVID-19 frena la tendencia positiva de visitas a los museos estatales en 2020, cuyas cifras globales descienden un $63,55 \%$. https://bit.ly/3dXiq00

R Project. (2020). R: A Language and Environment for Statistical Computing. https://www.Rproject.org/

Riofrío Flores, M. D. P., Alvarado Peña, E., Cueva Chacón, P., y Guerra Chirinos, D. (2019). Agenda de sostenibilidad para los museos y centros expositivos de Lima: ruta para su incidencia en el desarrollo sostenible de la ciudad. Museo de Arte de Lima.

Ruiz Torres, D. (2011). Realidad aumentada, educación y museos. Revista ICONO 14. Revista Científica de Comunicación y Tecnologías Emergentes, 9(2), 212-226. https://doi. org/10.7195/ri14.v9i2.24 
Ruiz Torres, D. R., y Bellido Gant, M. L. (2017). Guías multimedia con realidad aumentada en los museos del siglo xxI. La virtualidad como parte integrante del discurso expositivo. MODOS: Revista de História da Arte, 1(1), 175-184. https://doi. org/10.24978/mod.v1i1.737

Satta, F. (2017). Las estrategias de comunicación digital de los museos en las redes sociales. Análisis de presencia y rendimiento de los museos de arte catalanes [Tesis doctoral, Universitat Rovira i Virgili]. https://bit.ly/3zYqBDv

Schweibenz, W. (2019). The Virtual Museum: an Overview of its Origins, Concepts, and Terminology. The Museum Review, 4(1), 1-29. https://bit.ly/2PVpC5c

Secretaría General de Comunicación de la Presidencia. (16 de marzo del 2020). El presidente Lenín Moreno decreta Estado de Excepción para evitar la propagación del COVID-19, Secretaría General de Comunicación de la Presidencia. https://bit. ly/35fl0ej

Secretaría Nacional de Planificación y Desarrollo. (2017). Plan Nacional de Desarrollo 2017-2021. Toda una Vida. https://bit.ly/35low0Q

Wickham, H. (2016). ggplot2: Elegant Graphics for Data Analysis. Springer-Verlag. 